\title{
Pengaruh Deforestasi Dan Tingkat Kebakaran Hutan Terhadap Tingkat Emisi Gas Rumah Kaca
}

\author{
Sri Maryani ${ }^{\text {a* }}$ \\ ${ }^{a}$ Badan Penelitian dan Pengembangan Daerah Provinsi Sumatera Selatan, Indonesia \\ *Email: smaryani2014@gmail.com \\ Diterima (received) 13 Desember 2019; disetujui (accepted) 1 Februari 2020; tersedia secara online (available online) 1 Februari 2020
}

\begin{abstract}
This study aims to determine the effect of the area of Forest Fire and Deforestation Figures on Green House Gas Emission Level. This study uses descriptive quantitative research, with statistical analytical methods. The data source is processed with the Importance-Performance Analysis, so that the area can be used as a reference in reducing the level of greenhouse gas emissions. The provinces of South Kalimantan, South Sumatra and Papua are areas prone to fires which are suspected not to be affected by the high level of Indonesia's deforestation within and outside the Forest Zone, but there may be other factors that play a role in the emergence of the forest fires. It is suspected that among the factors that can be a trigger factor for high levels of forest fires that are directly related to the increase in the number of greenhouse gas emissions, namely the distribution of the peat deposits.
\end{abstract}

Keywords: South Sumatera; deforestation; Importance-Performance Analysis; peat deposit

\begin{abstract}
Abstrak
Penelitian ini bertujuan untuk mengetahui pengaruh luas areal kebakaran hutan dan angka deforestasi terhadap tingkat emisi gas rumah kaca. Penelitian ini menggunakan jenis penelitian deskriptif kuantitatif, dengan metode statistik analitik. Sumber data tersebut diolah dengan ImportancePerformance Analysis, sehingga kawasan tersebut dapat dijadikan acuan dalam menurunkan tingkat emisi gas rumah kaca. Provinsi Kalimantan Selatan, Provinsi Sumatera Selatan, dan Provinsi Papua merupakan wilayah rawan kebakaran yang diduga tidak terpengaruh oleh tingginya tingkat deforestasi Indonesia di dalam dan di luar Kawasan Hutan, namun mungkin terdapat faktor lain yang berperan dalam munculnya kebakaran hutan. Diduga salah satu faktor yang dapat menjadi faktor pemicu tingginya tingkat kebakaran hutan yang berhubungan langsung dengan peningkatan jumlah emisi gas rumah kaca, yaitu sebaran endapan gambut.
\end{abstract}

Kata Kunci: Sumatera Selatan; penggundulan hutan; Analisis Penting-Kinerja; deposit gambut

\section{Pendahuluan}

Emisi CO yang berpengaruh langsung pada peningkatan gas rumah kaca (GRK) dari waktu ke waktu terus meningkat baik pada tingkat global, regional, nasional. Beberapa faktor yang diduga mempengaruhi peningkatan emisi CO tersebut antara lain semakin meningkatnya penggunaan energi dari bahan organik (fosil), perubahan tataguna lahan dan kebakaran hutan, serta peningkatan kegiatan antropogenik lainnya (Krisnawati, H. dkk., 2015). Dimana kebakaran hutan umumnya terjadi pada areal yang bervegetasi rendah atau yang telah mengalami degradasi (Nasution dkk., 2015). Penelitian ini bertujuan untuk mengetahui pengaruh luasan Area Kebakaran Hutan dan Angka Deforestasi terhadap kenaikan emisi gas rumah kaca. Faktor penggunaan lahan, perubahan tata guna lahan dan kehutanan diduga merupakan faktor utama dalam yang menyebabkan terjadinya peningkatan gas rumah kaca.

doi: https://doi.org/10.24843/blje.2020.v20.i01.p02

(C) 2019 by the authors; Content from this work may be used under the terms of the Creative Commons Attribution 3.0 licence. Any further distribution of this work must maintain attribution to the author(s) and the title of the work, journal citation and DOI. Published under licence by Udayana University, Indonesia. 


\section{Metode Penelitian}

Penelitian ini menggunakan penelitian kuantitatif deskiptif, dengan metode statistik analitik. Sumber data diperoleh dari dokumen Statistik lingkungan Hidup Indonesia tahun 2016, 2017 dan 2018 yang kemudian diolah dalam bentuk grafik dan tabel serta dianalisis dengan analisis kuadran - ImportancePeformance Analysis yang terdiri atas dua komponen yaitu analisis kuadran dan analisis kesenjangan (gap) (Monica, Y.D. dkk., 2013), sehingga didapatkan daerah yang dapat dijadikan acuan dalam menurunkan tingkat emisi gas rumah kaca.

\section{Hasil dan Pembahasan}

Pada periode tahun 2000-2016 (Gambar 1), terjadi kenaikan emisi gas rumah kaca yang signifikan terutama pada tahun 2013-2016 yang bersumber dari sektor kebakaran hutan dan alih fungsi lahan. Kenaikan jumlah emisi gas rumah kaca ini merupakan penyebab terjadinya perubahan iklim dan akan memicu bencana alam diantaranya banjir, tanah longsor, kekeringan dll. Kebakaran hutan dan kegiatan alih fungsi lahan kehutanan yang berupakan dua sektor penyumbang utama emisi Gas Rumah Kaca (GRK) yang menyebabkan perubahan iklim global di Indonesia. Besarnya kontribusi sektor kehutanan sebagai penghasil utama emisi GRK dapat disebabkan karena peristiwa kebakaran hutan dan lahan gambut yang terjadi berulang hampir setiap tahun. Peristiwa kebakaran pada lahan gambut akan menyebabkan terlepasnya simpanan karbon yang selama bertahun-tahun tersimpan di dalamnya.

Kegiatan eksploitasi kawasan hutan merupakan faktor utama penyebab lahan kritis. Lahan kritis tidak berfungsi dengan baik sebagai media produksi untuk menumbuhkan tanaman budidaya maupun lainnya. Suatu lahan ditetapkan sebagai lahan kritis mengacu pada kondisi tutupan lahan, erosi, siklus hara, pengatur iklim mikro dan retensi karbon. Kegiatan Eksploitasi lahan kehutanan akan menyumbang pada semakin berkurangnya tutupan hutan Indonesia (deforestasi).

Indonesia sebagai negara dalam urutan luasan hutan sebesar $884,850 \mathrm{~km}^{2} \mathrm{ke} 9$ terluas di dunia (Wikipedia, n.d.), tetapi saat ini luas kawasan hutan Indonesia semakin menghilang sehingga saat ini hanya tersisa sekitar 125,9 juta hektare (ha) atau seluas 63,7 persen dari luas daratan Indonesia. Hal inilah yang membuat semakin tingginya tingkat emisi karbon di Indonesia.

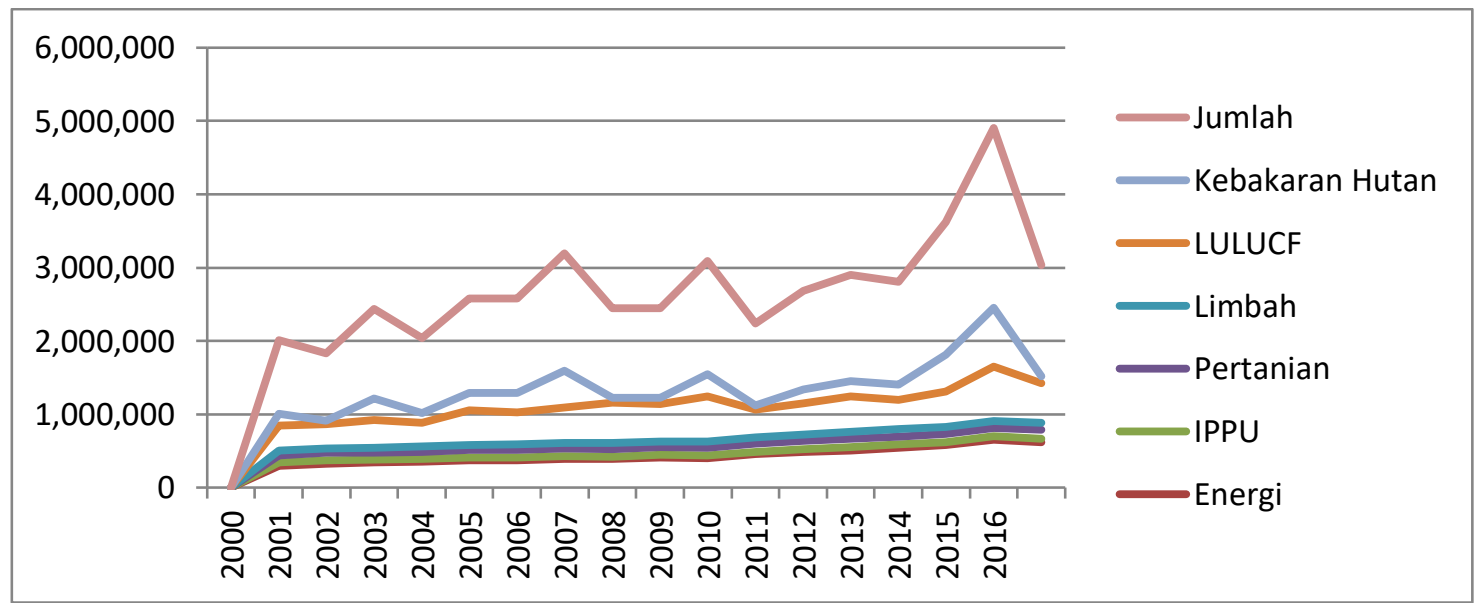

Keterangan: LULUCF=Land Use, Land Use Change and Forestry (Penggunaan lahan, perubahan penggunaan lahan dan sektor kehutanan)

IPPU=Industrial Process and Product Use

Gambar 1. Grafik emisi gas rumah kaca di indonesia menurut jenis sektor (ribu ton CO2e), 2010-2016 
Dari data rekapitulasi luas kebakaran hutan dan lahan (ha) per provinsi di Indonesia Tahun 20142019 (Gambar 2), provinsi Sumatera Selatan, Papua, Kalimantan Selatan dan Riau merupakan 4 provinsi yang memiliki luasan area Karhutla tertinggi. Provinsi Sumatera Selatan merupakan daerah dengan luasan Karhutla tertinggi walaupun kenaikan luasan hutan produksi konversi terjadi tidak secara signifikan dalam periode 2014 -2016 (sumber data diolah). Dampak kebakaran sebenarnya akanlangsung dirasakan manusia yaitu berupa kerugian ekonomis yaitu hilangnya manfaat dari potensi hutanseperti tegakan pohon hutan yang biasa digunakan manusia untuk memenuhi kebutuhannya (Rasyid, F., 2014).

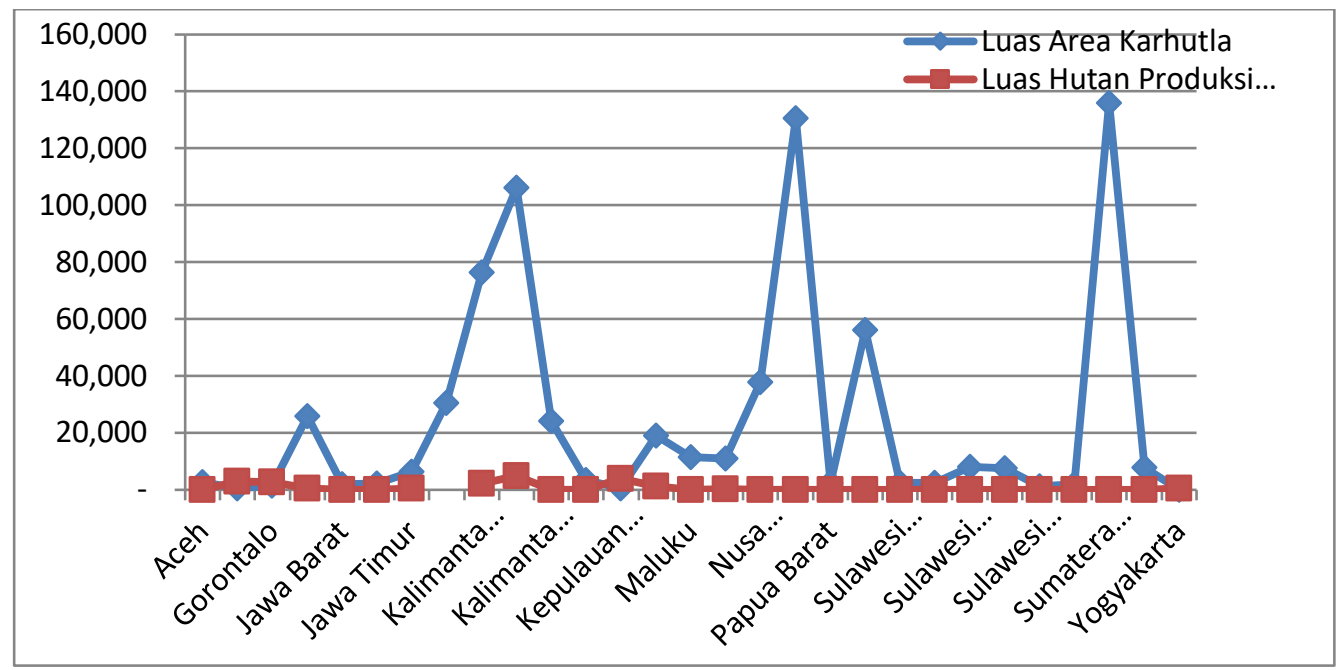

Gambar 2. Rekapitulasi luas kebakaran hutan dan lahan (ha) per provinsi di Indonesia Tahun 2014-2019.

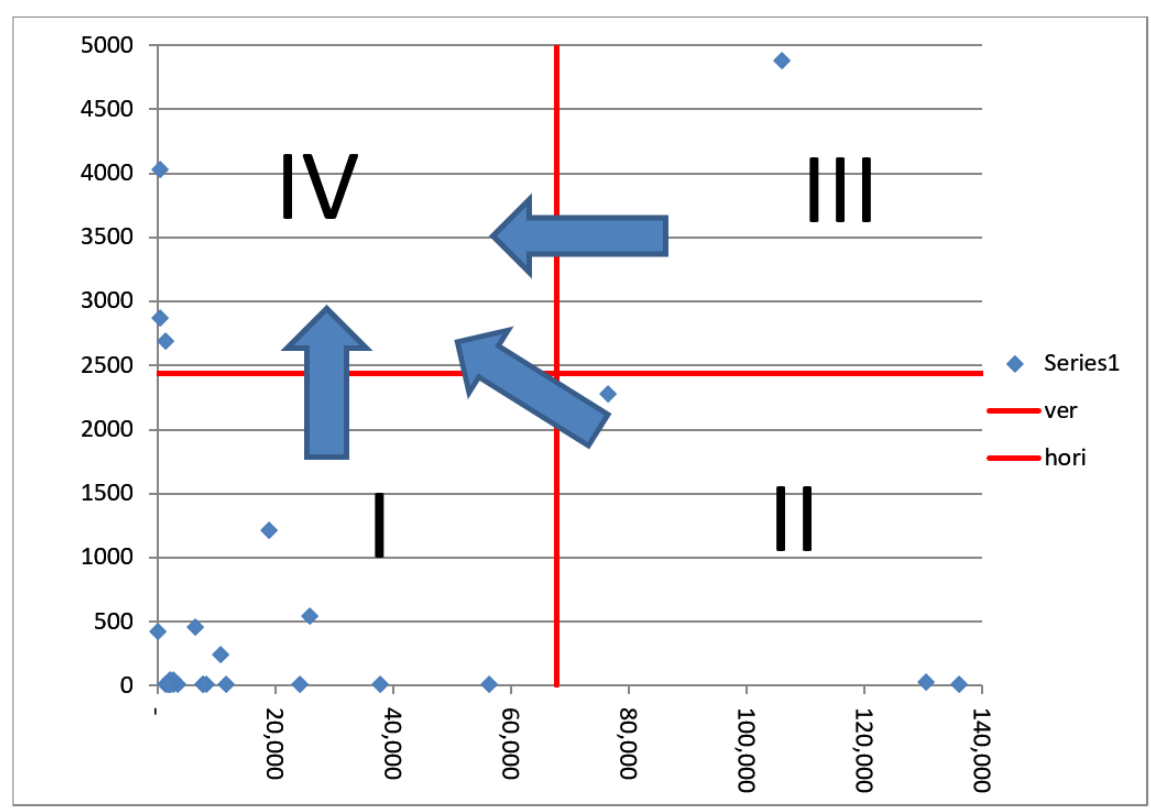

Keterangan: $\mathrm{X}=$ Luasan Karhutla tiap provinsi di Indonesia

$\mathrm{Y}=$ Angka Deforestasi (Netto) Indonesia di Dalam dan di Luar Kawasan Hutan (ha/tahun), 2014-2018

Gambar 3. Grafik Kuadran Luasan Karhutla vs Angka Deforestasi Indonesia (2014-2018). 
Tabel 1. Data luasan karhutla dan angka deforestasi (netto) indonesia di dalam dan di luar kawasan hutan (ha/tahun), 2014-2016

\begin{tabular}{|c|c|c|}
\hline Provinsi & Luas Karhutla & Hutan Produksi Konservasi \\
\hline Aceh & 2583,7 & 50,2 \\
\hline Bengkulu & 415,5 & 2869,1 \\
\hline Gorontalo & 1532,2 & 2686,9 \\
\hline Jambi & 25777,3 & 531,2 \\
\hline Jawa Barat & 2047,8 & 48,2 \\
\hline Jawa Tengah & 2247,9 & 0,0 \\
\hline Jawa Timur & 6334,6 & 456,0 \\
\hline Kalimantan Barat & 30474,5 & \\
\hline Kalimantan Selatan & 76529,5 & 2276,6 \\
\hline Kalimantan Tengah & 106213,0 & 4870,9 \\
\hline Kalimantan Timur & 24180,9 & 11,0 \\
\hline Kalimantan Utara & 3534,9 & 9,8 \\
\hline Kepulauan Riau & 469,4 & 4028,7 \\
\hline Lampung & 19138,4 & 1212,0 \\
\hline Maluku & 11568,7 & 0,0 \\
\hline Nusa Tenggara Barat & 10944,5 & 235,4 \\
\hline Nusa Tenggara Timur & 37782,7 & 8,7 \\
\hline Papua & 130664,2 & 31,7 \\
\hline Papua Barat & 2445,8 & 0,0 \\
\hline Riau & 56151,1 & 0,0 \\
\hline Sulawesi Barat & 2572,5 & 0,0 \\
\hline Sulawesi Selatan & 2361,5 & 13,4 \\
\hline Sulawesi Tengah & 8151,8 & 0,0 \\
\hline Sulawesi Tenggara & 7616,4 & 0,0 \\
\hline Sulawesi Utara & 1262,7 & 0,0 \\
\hline Sumatera Barat & 1892,6 & 0,0 \\
\hline Sumatera Selatan & 136046,8 & 0,0 \\
\hline Sumatera Utara & 7800,3 & 0,0 \\
\hline Yogyakarta & 0,3 & 414,5 \\
\hline
\end{tabular}

Terjadinya konversi lahan dari lahan yang bervegetasi menjadi lahan non vegetasi yang akan mengakibatkan penurunan cadangan karbon pada suatu penggunaan lahan (Setiawana, G. dkk., 2015). Berangkat dari hal ini di duga tingkat luasan karhutla sebagai penyebab tingginya emisi gas rumah kaca berbanding lurus dengan angka deforestasi. 
Dari analisis kuadran - Importance-Peformance Analysis diatas, pada Kuadran 1 merupakan provinsi yang Angka Deforestasi (Netto) Indonesia di Dalam dan di Luar Kawasan Hutan (rendah), Luasan Karhutla tiap provinsi di Indonesia (rendah). Kuadran 2 Merupakan provinsi dengan Angka Deforestasi (Netto) Indonesia di Dalam dan di Luar Kawasan Hutan (rendah), Luasan Karhutla tiap provinsi di Indonesia (tinggi). Provinsi Kalimantan Selatan, Sumatera Selatan dan Papua merupakan wilayah yang rawan akan kebakaran yang diduga tidak dipengaruhi oleh tinggi rendahnya Angka Deforestasi (Netto) Indonesia di Dalam dan di Luar Kawasan Hutan, tetapi kemungkinan ada faktor-faktor lain yang lebih berperan dalam timbulnya kebakaran hutan. Ditenggarai beberapa faktor yang dapat menjadi faktor pemicu tingginya tingkat kebakaran hutan yang berkaitan langsung dengan peningkatan angka emisi gas rumah kaca yaitu sebaran endapan gambut. Sebaran potensi endapan gambut berdasarkan lingkungan yang layak untuk dieksplorasi lebih lanjut, yang terdapat di Pulau Sumatera sekitar 4.587.190 Hektar, sedangkan sebaran potensi endapan gambut yang terdapat di Pulau Kalimantan sekitar 2.914.440 Hektar, yang meliputi Provinsi Kalimantan Barat, Kalimantan Tengah dan Kalimantan Selatan. (Tjahjono, J.A.E., 2006). Kebakaran pada kawasan hutan di Provinsi Riau tahun 2014 terjadi pada areal hutan gambut 92,43\%. dan lahan sawit (67,67\%), (Prayoto, 2011).

Pada kuadran 3 merupakan provinsi dengan Angka Deforestasi (Netto) Indonesia di Dalam dan di Luar Kawasan Hutan (tinggi), Luasan Karhutla tiap provinsi di Indonesia (tinggi), sedangkan pada kuadran 4 merupakan provinsi dengan: Angka Deforestasi (Netto) Indonesia di Dalam dan di Luar Kawasan Hutan (tinggi), Luasan Karhutla tiap provinsi di Indonesia (rendah).

\section{Simpulan}

Provinsi Kalimantan Selatan, Sumatra Selatan, dan Papua adalah daerah rawan kebakaran yang diduga tidak terpengaruh oleh tingginya tingkat deforestasi didalam dan di luar Kawasan Hutan, tetapi mungkin ada faktor-faktor lain yang berperan dalam munculnya kebakaran hutan. Diduga bahwa di antara faktor-faktor yang dapat menjadi faktor pemicu tingginya tingkat kebakaran hutan yang secara langsung berkaitan dengan peningkatan jumlah emisi gas rumah kaca, yaitu distribusi endapan gambut.

Dengan hasil ini diharapkan pemerintah dapat lebih mengarahkan kegiatan pembangunan yang berada dilahan gambut, untuk menurunkan tingkat kebakaran hutan yang juga akan menurunkan tingkat emisi.

\section{Daftar Pustaka}

Krisnawati, H. dkk. (2015). Metode Standar untuk Pendugaan Emisi Gas Rumah Kaca dari Sektor Kehutanan di Indonesia (Versi 1). Kementerian Lingkungan Hidup dan Kehutanan, Badan Penelitian dan Pengembangan Kehutanan.

Monica, Y. D. dkk. (2013). Kualitas Pelayanan Pada Bank Jawa Tengah (Studi Kasus: Bank Jateng Cabang Tembalang. Jurnal Gaussian, 2(4), 425-434.

Nasution dkk. (2013). Studi Emisi CO2 Akibat Kebakaran Hutan di Provinsi Riau (Studi Kasus di Kabupaten Siak. Jurnal Bumi Lestari, 13(1), 27 -36.

Prayoto. (2011). Analisis kebakaran hutan dan lahan gambut Provinsi Riau tahun 2014. Dalam Seminar International Inafor di IPB International Convention Center, Botani Square, Bogor 5-7 Desember 2011, Kerjasama FORDA, FORDEF, GAFORN, dan Asosiasi Kehutanan Bidang Planologi Dinas Kehutanan Provinsi Riau.

Rasyid, F. (2014). Permasalahan dan Dampak Kebakaran Hutan. Jurnal Lingkar Widyaiswara, 1(4), 4759.

Setiawana, G. dkk. (2015). Estimasi Hilangnya Cadangan Karbon Dari Perubahan Penggunaan Lahan Di Kabupaten Bogor. Jurnal Pengelolaan Sumberdaya Alam dan Lingkungan, 5(2), 141-147. doi:10.19081/jps1.5.2.141

Statistik Lingkungan Hidup Indonesia. (2016). BPS Indonesia

Statistik Lingkungan Hidup Indonesia. (2017). BPS Indonesia 
Statistik Lingkungan Hidup Indonesia. (2018). Pengelolaan Sampah di Indonesia. Indonesia: BPS Indonesia

Tjahjono, J.A.E. (2006). Kajian Potensi Endapan Gambut Indonesia Berdasarkan Aspek Lingkungan. Dalam Proceeding Pemaparan Hasil-Hasil Kegiatan Lapangan Dan Non Lapangan, Kelompok Program Penelitian Energi Fosil, Pusat Sumber Daya Geologi.

Wikipedia. (n.d.). Daftar negara menurut luas wilayah hutan. [online] Tersedia di: https://id.wikipedia.org/wiki/Daftar_negara_menurut_luas_wilayah_hutan, [diakses: 7 Juli 2019]. 